\title{
Practical Therapeutic Management of Percutaneous Atrial Septal Defect Closure
}

\author{
Shuhei Tanaka ${ }^{1}$, Teruhiko Imamura ${ }^{1}$, Nikhil Narang ${ }^{2}$, Nobuyuki Fukuda ${ }^{1}$, \\ Hiroshi Ueno ${ }^{1}$ and Koichiro Kinugawa ${ }^{1}$
}

\begin{abstract}
:
Atrial septal defects (ASDs) are one of the most common congenital heart disorders encountered by cardiologists. Percutaneous ASD closure for secundum ASD is commonly performed not only for children but also for adults, given its non-inferiority to surgical repair. The choice of closure technique should be based on assessing a patient's baseline comorbidities, including the presence of pulmonary hypertension, supraventricular tachycardias, and left ventricular diastolic dysfunction. Furthermore, anatomical features and defect types determined using echocardiography need to be considered when developing a management plan. Percutaneous closure is often the preferred method, given its comparable successful rate to surgical repair while also being far less invasive.
\end{abstract}

Key words: heart failure, intervention, catheter

(Intern Med Advance Publication)

(DOI: 10.2169/internalmedicine.5944-20)

\section{Background}

Atrial septal defects (ASDs) are the most commonly encountered congenital heart defect, accounting for nearly 35$40 \%$ of all adult congenital heart disease (1).> ASDs are stratified into secundum $(80 \%)$, primum $(15 \%)$, superior sinus venous defect $(5 \%)$, inferior sinus venous defect $(<1 \%)$, and unroofed coronary sinus $(<1 \%)$. Of note, the mortality of untreated patients with ASDs may be as high as $90 \%$ at 60 years of age (2). The majority of pediatric patients with ASDs are asymptomatic, whereas adult patients often have high rates of accompanying supraventricular arrhythmias, heart failure, and pulmonary hypertension. As a result, the therapeutic approach is determined based on the burden of underlying comorbid conditions.

Historically, surgical repair has been considered safe, with a high success rate approaching nearly $100 \%$ for both adults and pediatric patients in the absence of comorbidities $(3,4)$. With growing expertise, percutaneous ASD closure has become the preferred therapeutic strategy, demonstrating an excellent safety profile and high rate of procedural success (5-7), and became subject to reimbursement under the national insurance system in Japan in 2005. Higher-risk patients have since been able undergo non-surgical ASD closure without the risks associated with cardiopulmonary bypass while benefiting from a shorter hospitalization period (8-10). However, we should ensure that we are well aware of the potential procedure-related comorbidities and unique anatomical indications for percutaneous ASD closure.

We herein review the updated practical management and best practice procedural steps of percutaneous ASD closure therapy.

\section{Overview of Indication and Therapeutic Strategy}

In general, significant left to right shunt with right heart enlargement should prompt consideration for ASD closure (11). Percutaneous ASD closure is indicated only for the secundum types, whereas surgical closure is recommended for primum, sinus venosus, and unroofed coronary sinus (12). Partial anomalous pulmonary venous return may coexist in ASD patients with a sub-type of superior sinus venous defect or inferior sinus venous defect. However, the presence of longstanding septal defects may result in pro-

${ }^{1}$ Second Department of Internal Medicine, University of Toyama, Japan and ${ }^{2}$ Advocate Christ Medical Center, USA 
A

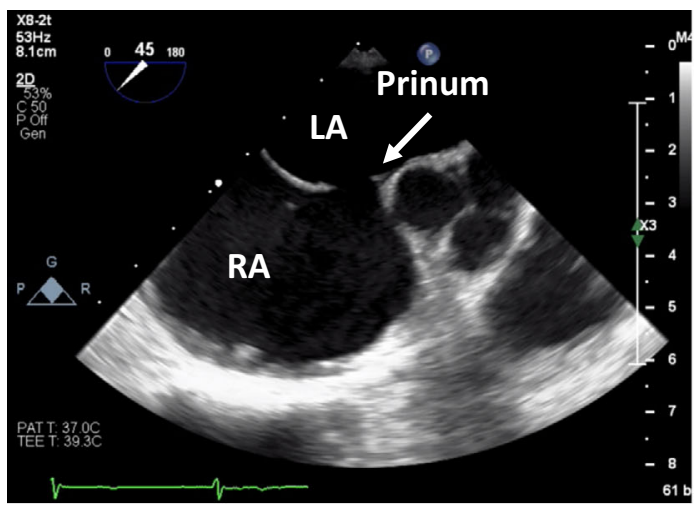

C

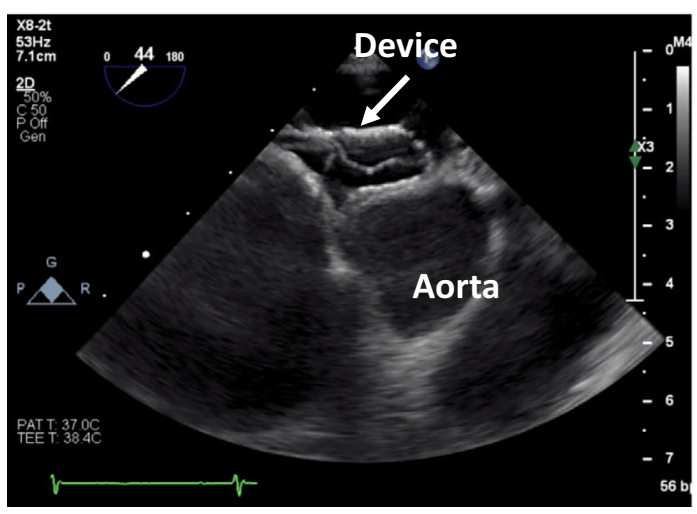

B

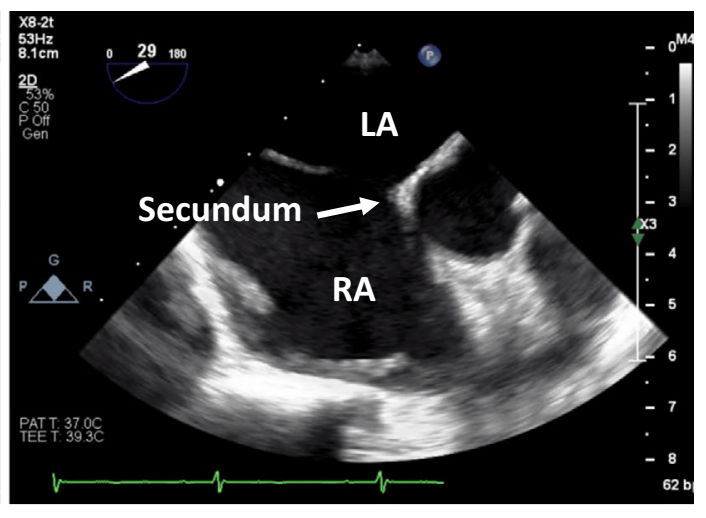

r
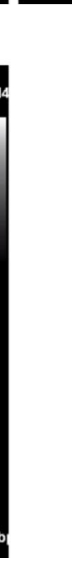

Figure 1. (A) (B) Secundum ASD with malalignment between the primum and secundum (red arrows), (C) A deployed Figulla Flex II in the flare shape.

gressive right ventricular adverse remodeling, resulting in a reduced chance of reversing right ventricular dysfunction following closure (13). Anatomical comorbidities should be assessed beforehand using transesophageal echocardiography and computed tomography to best plan a therapeutic strategy. Comorbid conditions, including atrial fibrillation, heart failure, and pulmonary hypertension, should be managed as best as possible prior to attempted ASD closure.

\section{Comorbidities Complicating with ASD}

\section{Atrial fibrillation or flutter}

Coexistent atrial fibrillation among patients with ASDs is exceedingly common. Indeed, approximately $13 \%$ of ASD patients over 40 years old have atrial fibrillation (8). The guidelines from the European Society of Cardiology recommend an attempt to restore sinus rhythm prior to ASD closure (14), especially since catheter ablation after ASD closure may become more challenging with the presence of intra-septal closure devices. In our institute, we assess patients for six months to check for recurrence of atrial fibrillation following catheter ablation prior to ASD closure.

\section{Heart failure}

Physiologically, there is initial left to right shunting in the presence of an ASD due to higher systemic pressures in the arterial circulation than in the venous system. The magnitude of the shunt depends on atrial compliance, the size of the defect, and the pressure gradient between the atria. In elderly patients, the degree of left to right shunting may often be greater than in younger patients due to decreased left atrial compliance caused by chronic hypertension. Postprocedurally, we expect to observe a decrease in the right heart size with improved left ventricular filling in addition to a reduction in the pulmonary pressure following ASD closure.

However, some patients may experience acute pulmonary edema following ASD closure due to an acute rise in the left atrial pressure (15). In our institute, we often temporarily occlude the defect using a balloon and then measure the left atrial pressure before the closure of the ASD, particularly in patients with echocardiographic and clinical signs of diastolic dysfunction.

\section{Pulmonary hypertension}

While the exact mechanism remains unknown, the prevalence of ASD-related pulmonary hypertension is reported to be around $7 \%$ (16). ASD closure is naturally contraindicated in patients with Eisenmenger syndrome, but it can often be safely performed in patients with mild pulmonary hypertension (pulmonary vascular resistance [PVR] $<5$ Wood Units) (17), In cases of more severe pulmonary hypertension with a PVR $\geq 5$ Wood Units, we perform a vasodilator chal- 


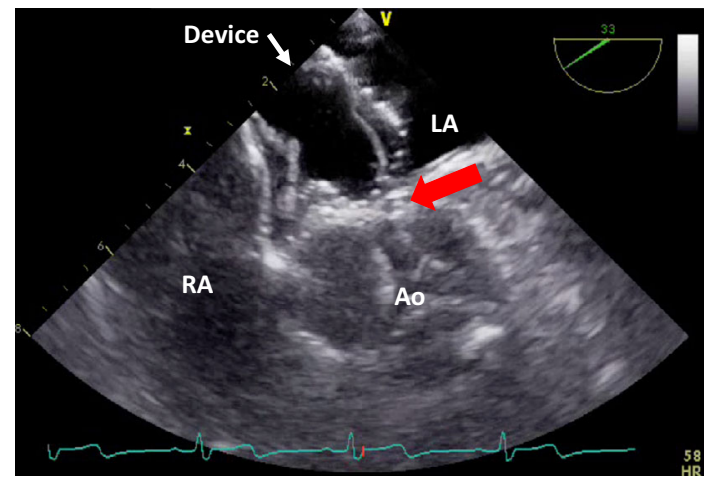

Figure 2. Placement of the device to achieve a flare shape while pushing the sinus of Valsalva (red arrow). This finding reflects a risk of cardiac erosion.

lenge prior to the ASD closure. Only patients with positive results, defined as a $>10-\mathrm{mmHg}$ decrease in the mean pulmonary artery pressure to achieve a mean pulmonary artery pressure $<40 \mathrm{mmHg}$ with a maintained cardiac output, are considered potential candidates for percutaneous ASD closure. Although few cases meet the positive criteria for this test, a decrease in PVR and an increase in shunt volume from left to right after administration of a pulmonary vasodilator are also findings suggesting reversibility of pulmonary hypertension, and ASD closure should thus be considered. Given the increased risk of potential complications in patients with more severe pulmonary hypertension, local anesthesia is preferred over general anesthesia.

Improvements in hemodynamics following the procedure vary among cases (18), with immediate reductions in the PVR seen in many patients although it may take months to see clinically significant reductions in the PVR for others. CHD-related pulmonary arterial hypertension (PAH), including ASD-related PAH, is histologically similar to idiopathic $\mathrm{PAH}$, including in its responsiveness to pulmonary vasodilators. Therefore, the therapeutic drug options offered are usually the same. As with severe idiopathic $\mathrm{PAH}$, intravenous prostacyclins, such as epoprostenol, are often used. Oral agents, including tadalafil, a phosphodiesterase-5 inhibitor, and riociguat, a soluble guanylate cyclase stimulator, have been reported to improve exercise tolerance and hemodynamics $(19,20)$. Recently, macitentan, a non-selective endothelin receptor antagonist reported to improve exercise tolerance and WHO functional classification in the SERAPHIN trial, has also been used (21), Combination oral therapy can also be considered, as it is commonly used in idiopathic PAH.

\section{Anatomical Features and Procedure-related Complications}

\section{Device selection}

Two devices in Japan are commercially available for percutaneous ASD clsoure: an Amplatzer Septal Occluder (Ab-
A
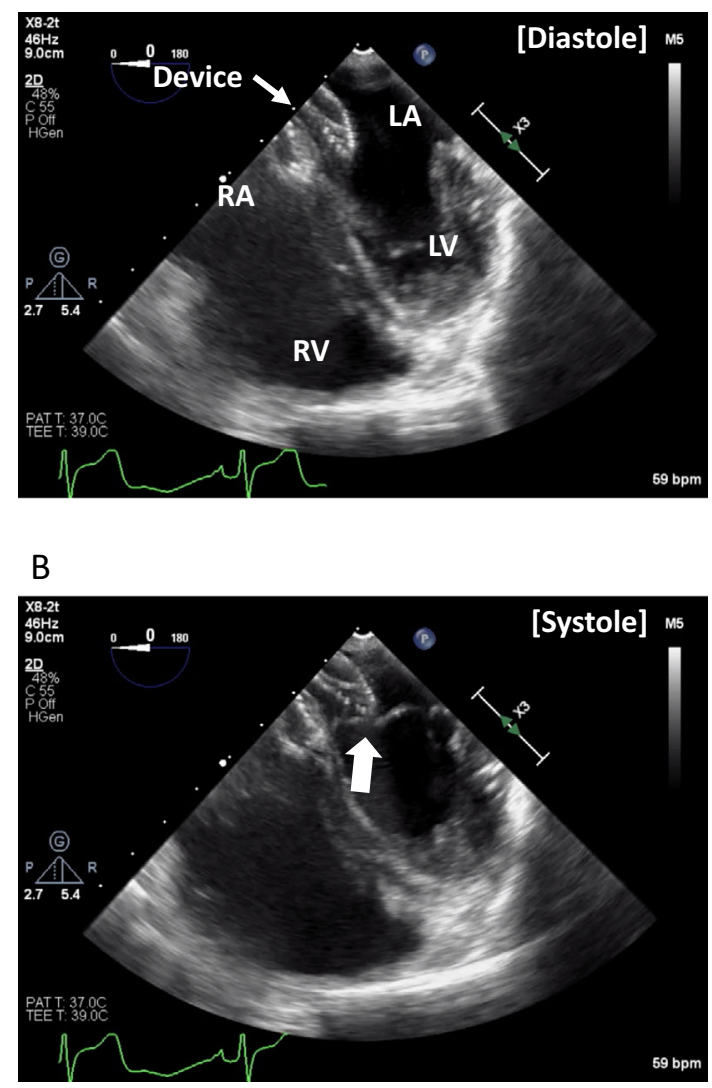

Figure 3. The device is in contact with the anterior mitral valve leaflet after device placement, and the mitral valve leaflet is pushing the device during the systolic phase. (A) diastolic phase, (B) systolic phase.

bott Vascular, Lake county, IL, USA) and Figulla Flex II (Occlutech GmbH, Helsingborg, Sweden) (22). In a case with multiple defects, the Amplatzer Cribriform Multifenestrated Septal Occluder (Abbott Vascular) is preferred (23).

The accepted indication of percutaneous ASD closure is a secundum defect with a maximal diameter below $38 \mathrm{~mm}$ and circumferential rim length over $5 \mathrm{~mm}$. However, the anatomical features of the defects vary among patients, with many not fitting within these accepted anatomical considerations (24).

There are published reports demonstrating the differences in clinical outcomes between the two devices.25 Amplatzer Septal Occluders can sandwich the atrial septum using bilateral discs and may minimize the risk of thromboembolic events, particularly in patients with a floppy rim. Given its flexibility and adaptability, the Figulla Flex II is particularly indicated for patients with aortic rim deficiency, characterized by a superior anterior rim length $\leq 5 \mathrm{~mm}$. In such cases, the device is deployed as a "flare shape" in the defect (26).

\section{Complications}

Percutaneous ASD close is non-inferior to surgical closure with regards to safety endpoints (27), However, two unique complications must be considered: cardiac erosion and device embolization. 

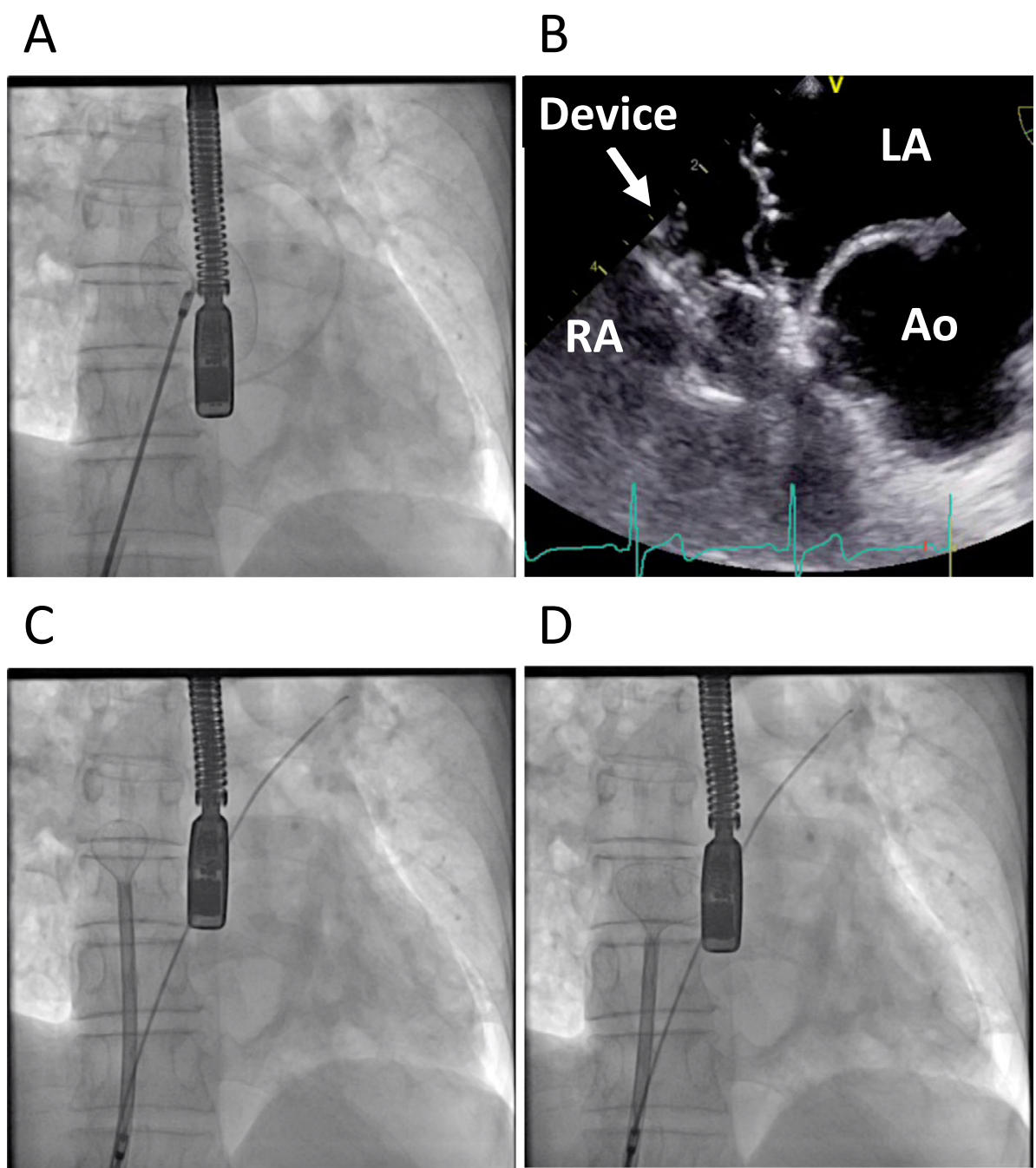

D

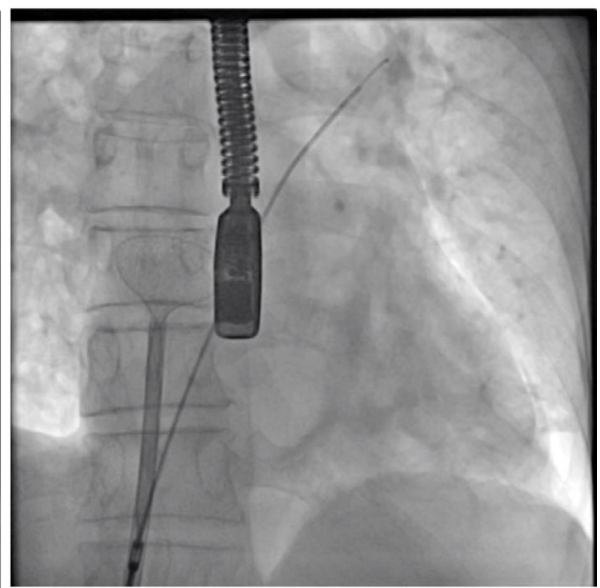

$\mathrm{E}$

$\mathrm{F}$
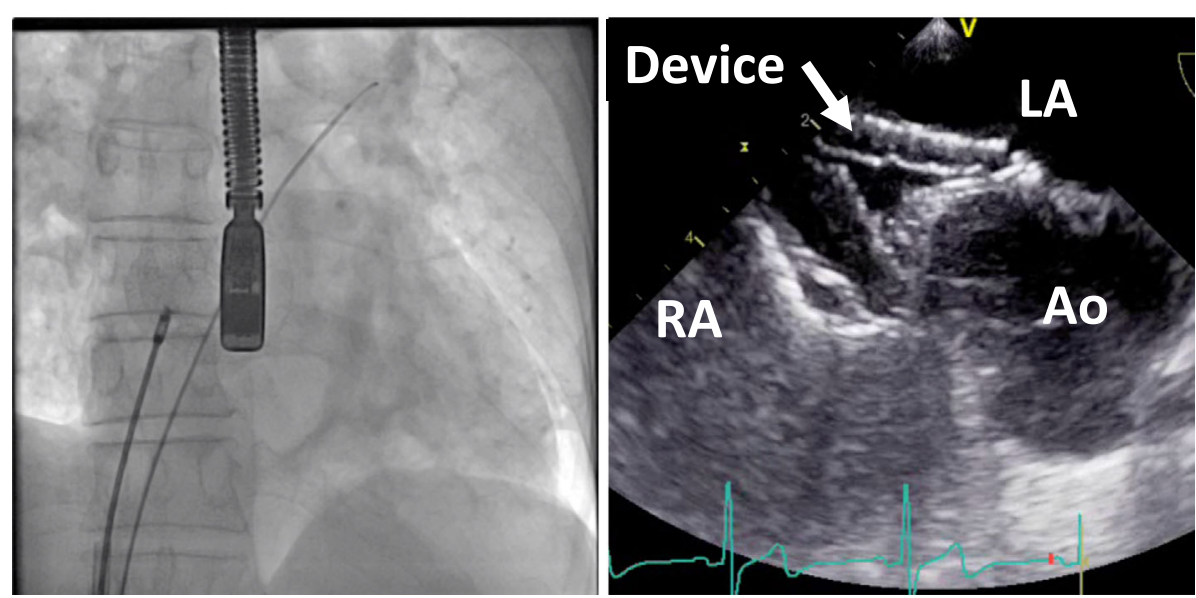

Figure 4. The catheter assist technique for secundum ASD with aortic rim deficiency. (A) (B) The device prolapses to the right atrium due to aortic rim deficiency. (C) Place the catheter through the ASD to the left upper pulmonary vein (LUPV), and (D) open the LA disc while keeping it in the LA by hooking it on the stiff wire passed through LUPV. (E) The device remains in the LA due to being supported by the catheter. (F) Flare-shaped ASD closure device implantation on TEE after detachment.

The incidence of cardiac erosion is approximately $0.2-$ $0.3 \%$ (28), for which the detailed mechanism remains uncertain. Amin et al. hypothesized a seesaw-like movement of the edge of the device near the superior rim during each cardiac cycle as a potential pathophysiologic cause (29), Specific risk factors for cardiac erosion include superior anterior 
A

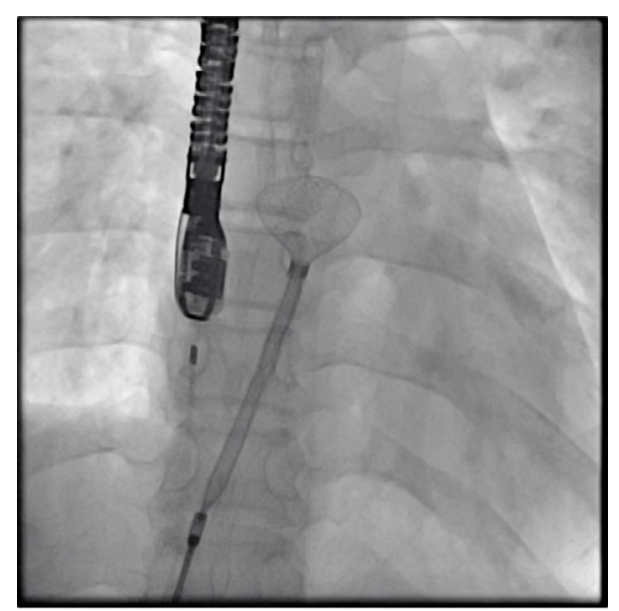

B

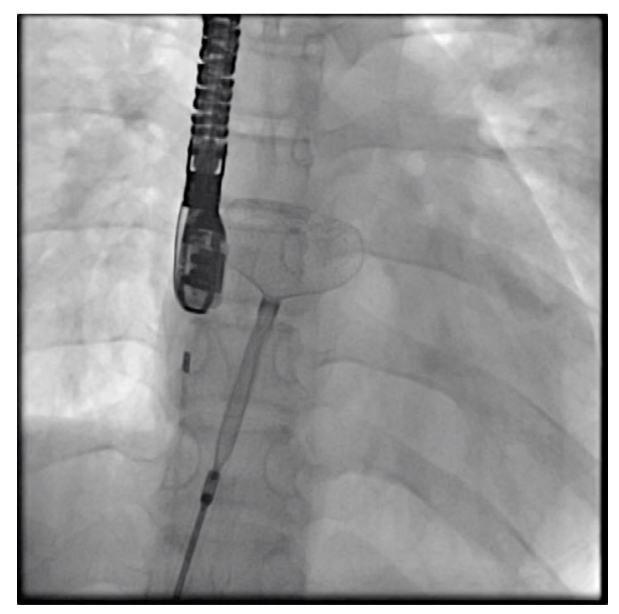

Figure 5. Using the mushroom technique to open the LA disc partially near the defect and further open the device while avoiding changing the position is effective in cases with a small left atrial size.

rim deficiency, malalignment between the primum and secundum, and an inappropriately large device size (30), Postclosure monitoring for pericardial effusion, which may signal potential cardiac erosion, is usually done within 24 hours post-procedure. Providers should also anticipate potential anatomical changes in the right atrial cavity size following device closure during follow-up. Cardiac erosion despite the selection of an appropriate device size may be associated with device-related compression of the sinus of Valsalva, irrespective of normal anatomical movement. Device "oversizing" may lead to aortic straddling, provide device stability, and prevent movement of the device relative to the heart, ultimately reducing the risk of erosion (31),

The incidence of device embolization is reported to be $0.6-1.5 \%(32,33)$. The most common risk factors for device embolization include undersizing, along with inadequate and floppy rim.
A

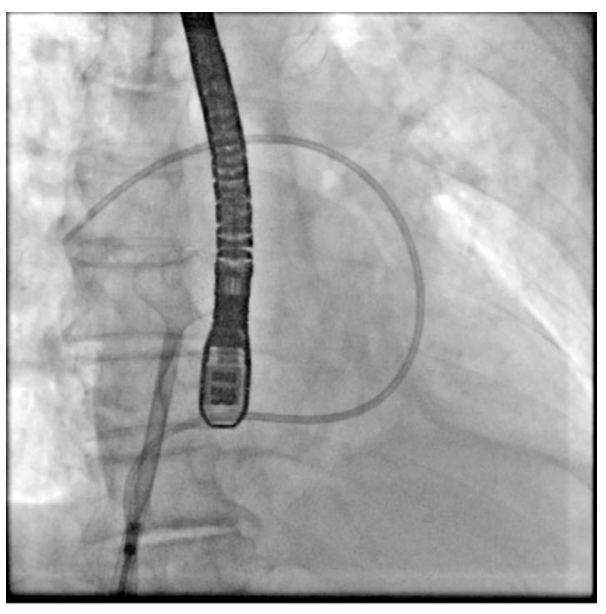

B

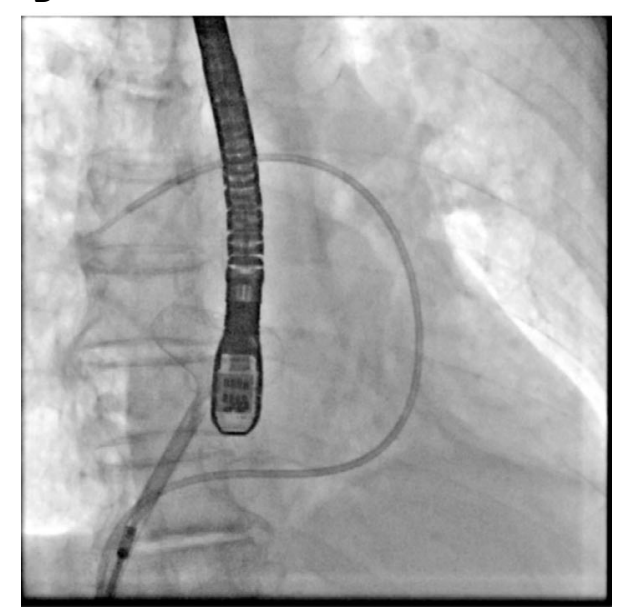

Figure 6. The right upper pulmonary vein (RUPV) technique. (A) The device in the sheath was brought into the RUPV. The LA disc was then opened in the LA (B) and hooked to the atrial septum.

\section{Practical Methodology of Percutaneous ASD Closure}

\section{Intra-procedural monitoring using echocardiography}

Echocardiography is an essential diagnostic tool in percutaneous ASD closure planning. Before the procedure, transesophageal echocardiography (TEE) is used to determine the indication. Important anatomical considerations are the size, location, and number of defects, along with the presence or absence of malalignment between the primum and secundum (Figure 1A,B). Percutaneous ASD closure is not indicated in cases with defects larger than $38 \mathrm{~mm}$ or extensive rim defects. Co-existing malformations should also be thoroughly evaluated by TEE. Periprocedurally, the operator should check for appropriate device apposition along the entire circumference of the atrial septum and also for any potential device interference with the surrounding tissue.

Intra-cardiac echocardiography (ICE) is another imaging modality often used during ASD closure. TEE has an advan- 
A

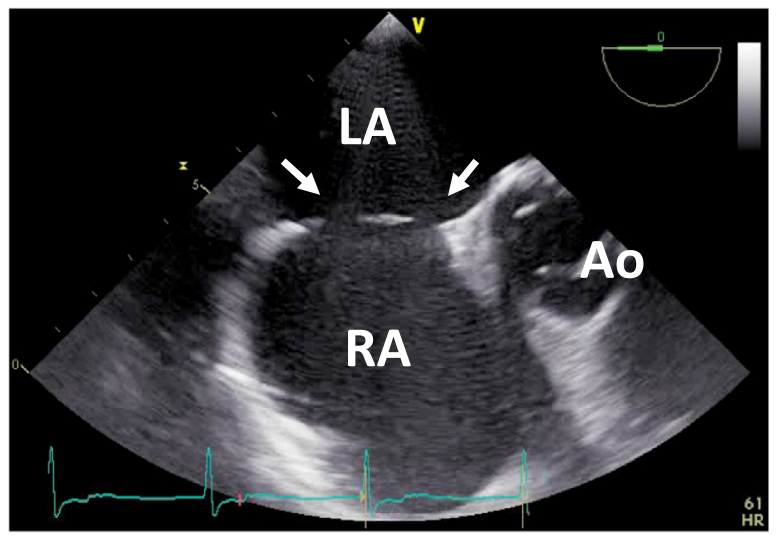

B

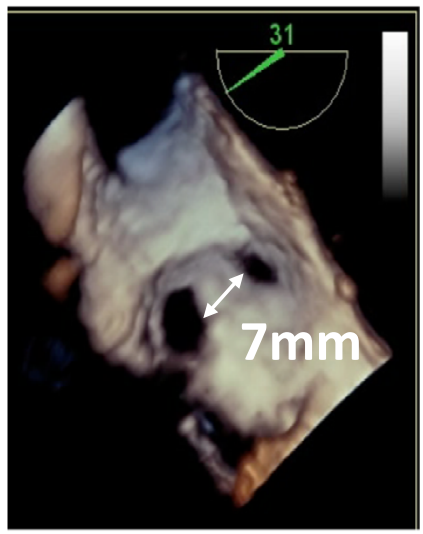

C

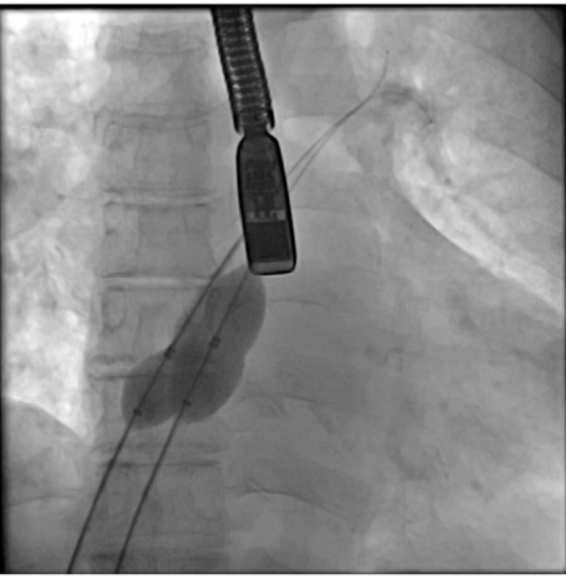

D

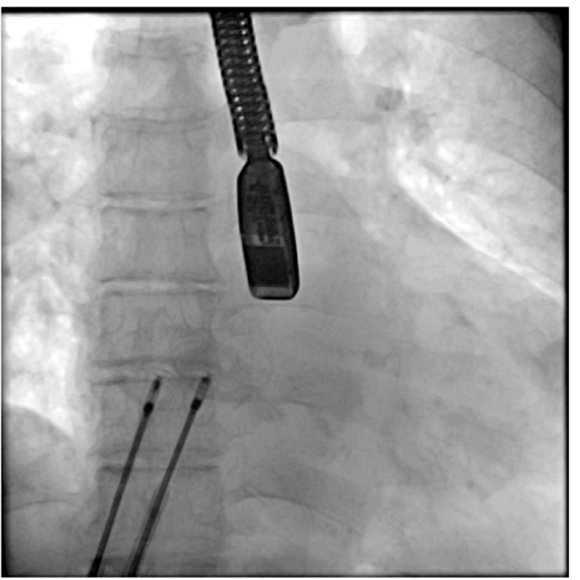

$\mathrm{E}$

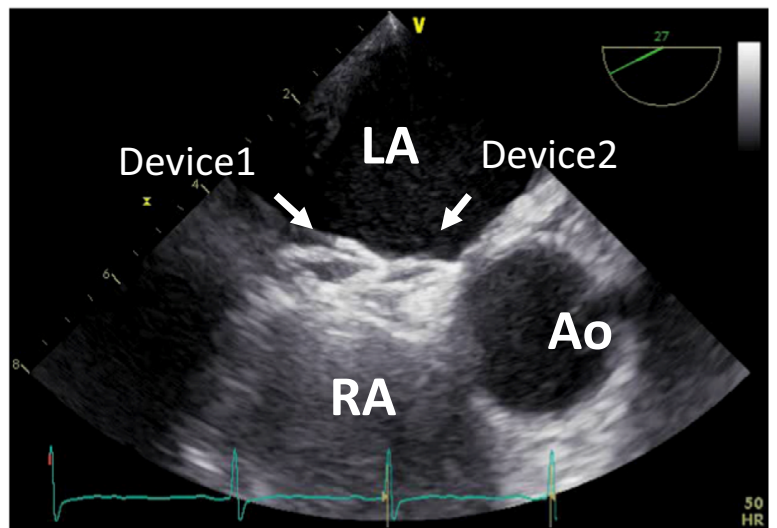

$\mathrm{F}$

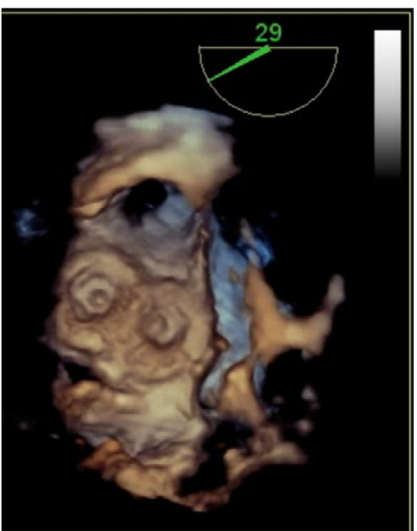

Figure 7. Treatment of multiple ASDs. (A) (B) 2D- and 3D-TEE imaging showed two isolated defects. The inter-ASD distance was $7 \mathrm{~mm}$. (C) Fluoroscopic imaging of simultaneous balloon sizing and (D) fluoroscopic imaging after placement of the two devices in multiple ASDs. (E) 2D-TEE and 3DTEE imaging findings after device placement showed that both devices were overlapping, and no interference with the surrounding tissue, such as the aorta, was observed.

tage in assessing the entire circumference of the defect but requires general anesthesia. ICE, by contrast, has an advantage in assessing the posterior-inferior rim, which sometimes cannot be adequately assessed by TEE. Utilizing ICE also has the advantage of not requiring general anesthesia (34),

\section{Procedural tips}

Recently, the balloon occlusion test has become less utilized in experienced institutions due to advances in threedimensional (3D) echocardiography $(35,36)$. Nevertheless, 
it is still beneficial not only to determine the appropriate device size but also to assess whether or not the left atrial pressure changes following defect closure (37), We perform the balloon occlusion test and confirm that the pulmonary artery wedge pressure remains static before device implantation. This becomes especially pertinent for elderly patients or those with severe left ventricular diastolic dysfunction, where the shunt defect serves as a left atrial "pop-off" valve.

In general, device size is determined by the tested maximal balloon size. Of note, the implanted device size should be larger than actually measured maximal balloon size in case of aortic rim deficiency in order to achieve a flare shape. For the same reason, a larger device size is required for those with malalignment between the primum and secundum (Fig. 1A, B) (38), When we use a flare shape technique (Fig. 1C), particular care must be taken to avoid contact between the device and aortic wall, which increases the risk of cardiac erosion (Fig. 2) (31), In cases requiring large device implantation, close attention is also needed to avoid interference between the left atrial disc and anterior mitral leaflet (Fig. 3A, B). Contact between the device and mitral valve might damage the anterior mitral leaflet, resulting in valve restriction and considerable valvular regurgitation.

In cases with a large ASD and complete deficiency of the superior and anterior rim, the device is at risk of prolapsing into the right atrium. Fig. 4 shows the technique of using a multipurpose catheter along the aortic side to the left superior pulmonary vein to prevent prolapse into the right atrial cavity when opening the device disc of the left atrial side. By sandwiching the catheter between the device and aorta, the device disc of the left atrial side can be placed in the flare shape while hooked to the device. A sizing balloon is also useful for device placement in cases of superior and anterior rim deficiency. When the disc of the left atrial side is pulled back toward the interatrial septum the disc on the left atrium side, the inflated sizing balloon in the right atrium is pushed against the interatrial septum that supports it. The closure device flared around the aorta can then be affixed to the septum by continuing to support the waist and disc of the right atrial side with a sizing balloon until it is partially opened (39),

In younger patients, we often observe a smaller left atrium, which in turn may prevent the device from fully opening into the left atrial cavity. In these situations, we might open the device partially in the upper pulmonary vei (40), or open the disc on the left atrial side, somewhat similar to a "mushroom" shape. We may also in such situations unfold the disc of the left atrial side without changing the position (Fig. 5A, B). When deploying via that method is difficult, it may allow us to bring the sheath perpendicularly into the atrial septum using a Haudorf-Lock Atrial Design sheath (COOK MEDICAL LCC, Bloomington, IN, USA) shaped in a 3D curve. Alternatively, deploying the left atrial disc via the right superior pulmonary vein instead of the left superior pulmonary vein may allow it to be deployed perpendicularly to the atrial septum (Fig. 6A, B).
This method also helps place the closure device in the flare shape in the aorta in cases with anterior superior rim deficiency.

Multiple ASDs are detected in approximately $10 \%$ of patients with ASDs (41), and in such cases, the distance between the defects is a key consideration. Since the device edge of the left atrial side is placed up to $6-8 \mathrm{~mm}$ from the defect in which the device is implanted, treatment with multiple closure devices is recommended if the distance between the defect holes is over $7 \mathrm{~mm}$, in order to prevent interference between the devices. It is common to close the smaller defect first in order to stabilize both devices by covering the larger device with the smaller one, but the order of the device implantation is not very important (Fig. 7A-F).

\section{Conclusion}

Percutaneous ASD closure is a recently introduced lessinvasive option for cases of secundum defects as well as for patients significantly burdened by comorbid conditions in whom surgery carries a high risk. Many unique clinical situations require expertise from high-volume centers in order to troubleshoot potential procedural challenges.

The authors state that they have no Conflict of Interest (COI).

\section{Disclosure}

TI receives grant support from JSPS KAKENHI: JP20K17143.

\section{References}

1. Geva T, Martins JD, Wald RM. Atrial septal defects. Lancet 383: 1921-1932, 2014.

2. Sebatian Udholm, Camilla Nyboe, Zarmiga Karunanithi, Anne Illemann. Christensen, Andrew Redington, Jens Erik NielsenKudsk, Vibeke E Hjortdal. Lifelong burden of small unrepaired atrial septal defect: Results from the Danish National Patient Registry. Int J Cardiol 283: 101-106, 2019.

3. Murphy JG, Gersh BJ, McGoon MD, et al. Long-term outcome after surgical repair of isolated atrial septal defect. Follow-up at 27 to 32 years. N Engl J Med 323: 1645-1650, 1990.

4. Meijboom F, Hess J, Szatmari A, et al. Long-term follow-up (9 to 20 years) after surgical closure of atrial septal defect at a young age. Am J Cardiol 72: 1431-1434, 1993.

5. Masura J, Gavora P, Formanek A, Hijazi ZM. Transcatheter closure of secundum atrial septal defects using the new self-centering amplatzer septal occluder: initial human experience. Cathet Cardiovasc Diagn 42: 388-393, 1997.

6. Fischer G, Kramer HH, Stieh J, Harding P, Jung O. Transcatheter closure of secundum atrial septal defects with the new selfcentering Amplatzer Septal Occluder. Eur Heart J. 20: 541-549, 1999.

7. Waight DJ, Koenig PR, Cao QL, Hijazi ZM. Transcatheter Closure of Secundum Atrial Septal Defects Using the Amplatzer Septal Occluder: Clinical Experience and Technical Considerations. Curr Interv Cardiol Rep 2: 70-77, 2000.

8. Du ZD, Hijazi ZM, Kleinman CS, Silverman NH, Larntz K, Amplatzer I. Comparison between transcatheter and surgical closure of secundum atrial septal defect in children and adults: results of a multicenter nonrandomized trial. J Am Coll Cardiol 39: 18361844, 2002.

9. Mylotte D, Quenneville SP, Kotowycz MA, et al. Long-term costeffectiveness of transcatheter versus surgical closure of secundum atrial septal defect in adults. Int J Cardiol 172: 109-14, 2014. 
10. Rosas M, Zabal C, Garcia-Montes J, Buendia A, Webb G, Attie F. Transcatheter versus surgical closure of secundum atrial septal defect in adults: impact of age at intervention. A concurrent matched comparative study. Congenit Heart Dis. 2: 148-55, 2007.

11. Attie F, Rosas M, Granados N, Zabal C, Buendia A, Calderon J. Surgical treatment for secundum atrial septal defects in patients $>$ 40 years old. A randomized clinical trial. J Am Coll Cardiol 38: 2035-42, 2001

12. Warnes CA, Williams RG, Bashore TM, et al. ACC/AHA 2008 guidelines for the management of adults with congenital heart disease: a report of the American College of Cardiology/American Heart Association Task Force on Practice Guidelines (Writing Committee to Develop Guidelines on the Management of Adults With Congenital Heart Disease). Developed in Collaboration With the American Society of Echocardiography, Heart Rhythm Society, International Society for Adult Congenital Heart Disease, Society for Cardiovascular Angiography and Interventions, and Society of Thoracic Surgeons. J Am Coll Cardiol 52: e143-e263, 2008.

13. Umemoto S, Sakamoto I, Abe K, et al. Preoperative Threshold for Normalizing Right Ventricular Volume After Transcatheter Closure of Adult Atrial Septal Defect. Circ J 2020.

14. Baumgartner H, Bonhoeffer P, De Groot NM, et al. Task Force on the Management of Grown-up Congenital Heart Disease of the European Society of C, Association for European Paediatric C, Guidelines ESCCfP. ESC Guidelines for the management of grown-up congenital heart disease (new version 2010). Eur Heart J 31: $2915-2957,2010$

15. Ewert P, Berger F, Nagdyman N, et al. Masked left ventricular restriction in elderly patients with atrial septal defects: a contraindication for closure? Catheter Cardiovasc Interv 52: 177-80, 2001.

16. Duffels MG, Engelfriet PM, Berger RM, et al. Pulmonary arterial hypertension in congenital heart disease: an epidemiologic perspective from a Dutch registry. Int J Cardiol 120: 198-204, 2007.

17. Balint $\mathrm{OH}$, Samman A, Haberer K, et al. Outcomes in patients with pulmonary hypertension undergoing percutaneous atrial septal defect closure. Heart 94: 1189-93, 2008.

18. Zwijnenburg RD, Baggen VJM, Geenen LW, et al. The prevalence of pulmonary arterial hypertension before and after atrial septal defect closure at adult age: A systematic review. Am Heart J 201: 63-71, 2018.

19. Galiè N, Brundage BH, Ghofrani HA, et al. Pulmonary Arterial Hypertension and Response to Tadalafil (PHIRST) Study Group: Tadalafil therapy for pulmonary arterial hypertension. Circulation 119: 2894-2903, 2009.

20. Rubin LJ, Galiè N, Grimminger F, et al. Riociguat for the treatment of pulmonary arterial hypertension: A long-term extension study (PATENT-2). Eur Respir J 45: 1303-1313, 2015.

21. Pulido T, Adzerikho I, Channick RN, et al. SERAPHIN Investigators: Macitentan and morbidity and mortality in pulmonary arterial hypertension. N Engl J Med 369: 809-818.4, 2013.

22. Trabattoni D, Gaspardone A, Sgueglia GA, et al. AMPLATZER versus Figulla occluder for transcatheter patent foramen ovale closure.. EuroIntervention 12: 2092-2099, 2017.

23. Numan M, El Sisi A, Tofeig M, Gendi S, Tohami T, El-Said HG. Cribriform amplatzer device closure of fenestrated atrial septal defects: feasibility and technical aspects. Pediatr Cardiol 29: 530$535,2008$.

24. Podnar T, Martanovic P, Gavora P, Masura J. Morphological variations of secundum-type atrial septal defects: feasibility for percutaneous closure using Amplatzer septal occluders. Catheter Cardiovasc Interv 53: 386-391, 2001

25. Fujii Y, Akagi T, Nakagawa K, et al. Clinical impact of transcatheter atrial septal defect closure on new onset atrial fibrillation in adult patients: Comparison with surgical closure. J Cardiol 2020.

26. Snijder RJR, Renes LE, Bosshardt D, Suttorp MJ, Ten Berg JM,
Post MC. Percutaneous Atrial Septal Defect Closure Using the Occlutech Figulla Device in Adults: More than 800 Patient-Years of Follow-Up. J Interv Cardiol 2020: 7136802, 2020.

27. Butera G, Biondi-Zoccai G, Sangiorgi G, et al. Percutaneous versus surgical closure of secundum atrial septal defects: a systematic review and meta-analysis of currently available clinical evidence. EuroIntervention 7: 377-385, 2011.

28. DiBardino DJ, McElhinney DB, Kaza AK, Mayer JE Jr. Analysis of the US Food and Drug Administration Manufacturer and User Facility Device Experience database for adverse events involving Amplatzer septal occluder devices and comparison with the Society of Thoracic Surgery congenital cardiac surgery database. J Thorac Cardiovasc Surg 137: 1334-1341, 2009.

29. Zahid Amin, Ziyad M Hijazi, John P Cheatham, William E Hellenbrand, Charles S Kleinman. Erosion of Amplatzer septal occluder device after closure of secundum atrial septal defects: review of regstry of complications and recommendations to minimize future risk. Catheter Cardiovasc Interv 63: 496-502, 2004.

30. McElhinney DB, Quartermain MD, Kenny D, Alboliras E, Amin Z. Relative Risk Factors for Cardiac Erosion Following Transcatheter Closure of Atrial Septal Defects: A Case-Control Study. Circulation 133: 1738-1746, 2016.

31. Howaida G El-Said, John W Moore. Erosion by the Amplatzer septal occluder: experienced operator opinions at odds with manufacturer recommendations?. Catheter Cardiovasc Interv 73: 925930, 2009.

32. Levi DS, Moore JW. Embolization and retrieval of the Amplatzer septal occluder. Catheter Cardiovasc Interv 61: 543-547, 2004.

33. El-Said H, Hegde S, Foerster S. Device therapy for atrial septal defects in a multicenter cohort: acute outcomes and adverse events. Catheter Cardiovasc Interv 85: 227-233, 2015.

34. Budts W, Troost E, Voigt JU, Gewillig M. Intra-cardiac echocardiography in atrial septal interventions: impact on hospitalization costs. Acta Cardiol 65: 147-152, 2010.

35. Şakir Arslan, Göksel Çağırcı, Nermin Bayar, et al. Corrected balloon occlusive diameter to determine device size during percutaneous atrial septal defect closure. Turk Kardiyol Dern Ars 43: 420426, 2015.

36. JeongYoon Jang, Ran Heo, Min Soo Cho, et al. Efficacy of 3D transoesophageal echocardiography for transcatheter device closure of atrial septal defect without balloon sizing. Eur Heart J Cardiovasc Imaging. 19: 684-689, 2018.

37. William R Miranda, Donald J Hagler, Guy S Reeder, Carole A Warnes, Heidi M Connolly, Alexander C Egbe, NathanielW Taggart. Temporary balloon occlusion of atrial septal defects in suspected or documented left ventricular diastolic dysfunction: Hemodynamic and clinical findings. Catheter Cardiovasc Interv 93: 1069-1075, 2019.

38. Yoichi Takaya, Teiji Akagi, Koji Nakagawa, et al. Clinical Significance of Septal Malalignment for Transcatheter Closure of Atrial Septal Defect. J Interv Cardiol 2020: 6090612, 2020.

39. Dalvi BV, Pinto RJ, Gupta A. New technique for device closure of large atrial septal defects. Catheter Cardiovasc Interv 64: 102-107, 2005.

40. Varma C, Benson LN, Silversides C, et al. Outcomes and alternative techniques for device closure of the large secundum atrial septal defect. Catheter Cardiovasc Interv 61: 131-139, 2004.

41. Diab KA, Cao QL, Bacha EA, Hijazi ZM. Device closure of atrial septal defects with the Amplatzer septal occluder: safety and outcome in infants. J Thorac Cardiovasc Surg 134: 960-966, 2007.

The Internal Medicine is an Open Access journal distributed under the Creative Commons Attribution-NonCommercial-NoDerivatives 4.0 International License. To view the details of this license, please visit (https://creativecommons.org/licenses/ by-nc-nd/4.0/).

(C) The Japanese Society of Internal Medicine Intern Med Advance Publication 